\title{
Spasm of left main coronary artery
}

\author{
Dan Tzivoni, Gideon Merin, Simcha Milo, and Mervyn S. Gotsman \\ From the Cardiac Service, and Department of Cardio-Thoracic Surgery, Hebrew University-Hadassah Medical \\ School, ferusalem, Israel
}

\begin{abstract}
A 46-year-old male patient with atypical angina pectoris appeared to have an important elongated stenosis of the left main coronary artery on coronary arteriography, and slight irregularities in the left anterior descending, circumflex, and right coronary arteries. A saphenous vein bypass graft to the left anterior descending artery was performed, and this relieved the patient's symptoms. Postoperative coronary arteriography demonstrated a widely patent left main coronary artery and graft. The original narrowing of the left main coronary artery was probably caused by spasm and the source of the patient's anginal symptom.
\end{abstract}

Coronary artery spasm has been proven experimentally in animals (Gensini et al., 1962) and angiographically in patients with angina pectoris (Oliva, Potts, and Pluss, 1973; Dhurandhar et al., 1972). It is probably an important factor in variant angina pectoris (Prinzmetal et al., 1959; MacAlpin, Kattus, and Alvaro, 1973) and may be a precipitating factor in acute myocardial infarction. Spasm may occur in patients with normal coronary arteries (King et al., 1973) and may be the cause of myocardial infarction, arrhythmias, and possibly sudden death.

Previous reports have described spasm of the right coronary artery (Oliva et al., I973; O'Reilly, Spellberg, and King, 1970). In contrast, we describe a patient with spasm leading to narrowing of the left main coronary artery which we suspected to be caused by an organic lesion. He underwent saphenous vein bypass graft implantation, but subsequent angiographic examination showed a patent, normal left main coronary artery.

\section{Case report}

A 46-year-old bus driver was admitted for coronary arteriography. A year before admission he complained of praecordial pain which radiated to the left shoulder and was not clearly related to effort. He was admitted to hospital twice with severe chest pain with transient $T$ wave inversion in the praecordial leads, but without signs of acute myocardial infarction. He had mild diabetes mellitus (fasting blood glucose level of $130 \mathrm{mg} /$ IOO $\mathrm{ml}(7.2 \mathrm{mmol} / \mathrm{l})$ ), type 4 hyperlipidaemia (serum triglyceride $400 \mathrm{mg} / 100 \mathrm{ml}(4.5 \mathrm{mmol} / \mathrm{l})$, cholesterol
$300 \mathrm{mg} / 100 \mathrm{ml}(7.8 \mathrm{mmol} / \mathrm{l}))$, and smoked 60 cigarettes a day.

Physical examination was non-contributory. Blood pressure: $135 / 90 \mathrm{mmHg}$ (18.0/12.0 kPa). There were no signs of heart failure, the heart was not enlarged, and the heart sounds were normal. Electrocardiogram showed sinus rhythm at a rate of 100 a minute, and flat $T$ waves in the praecordial leads. The chest $x$-ray was normal.

Selective coronary arteriography was performed using the Judkins' technique (Judkins, 1967; Gotsman et al., r973) with premedication of diazepam ro $\mathrm{mg}$ and pethidine $50 \mathrm{mg}$. Atropine was not given because of sinus tachycardia: nor was sublingual isosorbide dinitrate given. A $4 \mathrm{~cm}$ Judkins left coronary catheter was introduced first. The left coronary artery ostium was intubated repeatedly but in each instance blood pressure fell: the tip of the catheter was withdrawn promptly. After several entries into the ostium, the blood pressure did not change and blood could be aspirated freely from the catheter. An injection of $3 \mathrm{ml}$ Renografin 76 was made, and screening suggested obstruction of the left main coronary artery immediately beyond its origin: the catheter was withdrawn immediately. The arterial pressure fell slowly and severe bradycardia occurred: this did not respond to $2 \mathrm{mg}$ intravenous atropine, the patient lost consciousness, and the electrocardiogram showed cardiac standstill. Cardiac resuscitation was successful, the patient regained consciousness, blood pressure returned to normal, and the electrocardiogram returned to its previous pattern.

The patient was allowed to recover for 90 minutes. A temporary pacemaker was inserted with its tip at the apex of the right ventricle and further selective injections were made into the right coronary artery. Each injection was followed by a fall in blood pressure and severe $T$ wave inversion. 


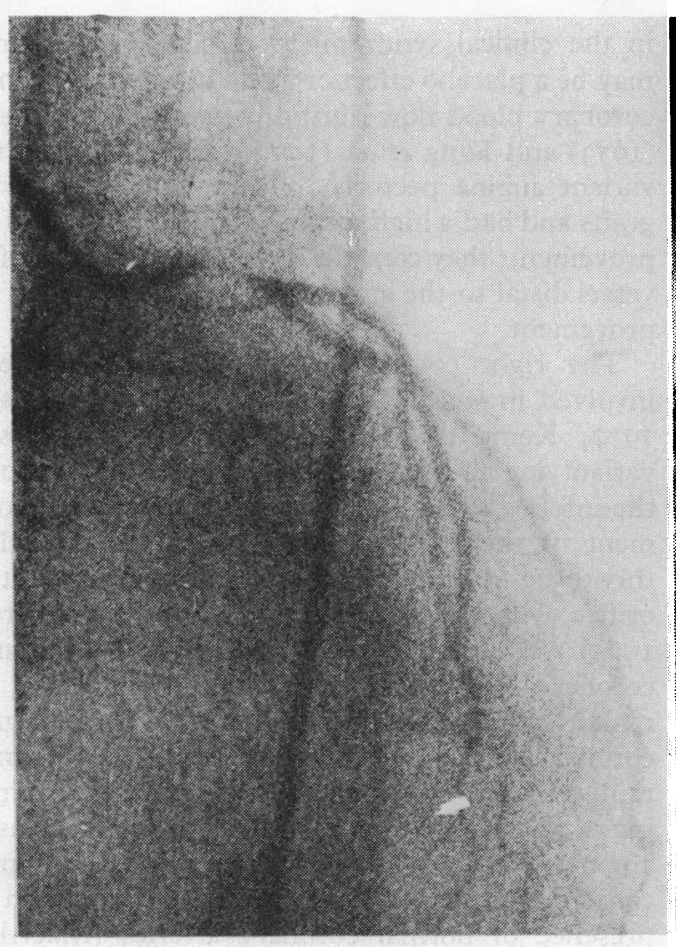

FIG. I Preoperative, selective left coronary arteriogram ( $A P$ position) shows severe elongated narrowing of the middle two-thirds of the main left coronary artery. The remainder of the artery and its branches show slight irregularities.

The cineangiogram showed a 95 per cent obstruction affecting a long segment of the left main coronary artery (Fig. I): the left anterior descending and circumflex arteries and their branches showed slight irregularities. The right coronary artery was normal and no collateral filling of the left coronary system was observed. Because of the potentially lethal nature of the suspected left main coronary obstruction and the clinical reaction to left coronary angiography, further selective injections into the left artery were not made and it was decided to submit the patient to immediate operation. Several observers doubted the organic nature of the obstruction since the other vessels did not show major obstructions and collateral vessels from the right coronary artery were not seen. The possibility of spasm of the artery or dissection of the intima were suggested.

At operation no gross atheromatous lesions could be palpated. Upon incision of the left anterior descending artery excellent forward flow of blood was noticed. Nevertheless, a reversed saphenous vein bypass graft was inserted between the aorta and the proximal third of the left anterior descending artery. The flow through the graft was $60 \mathrm{ml} / \mathrm{min}$.

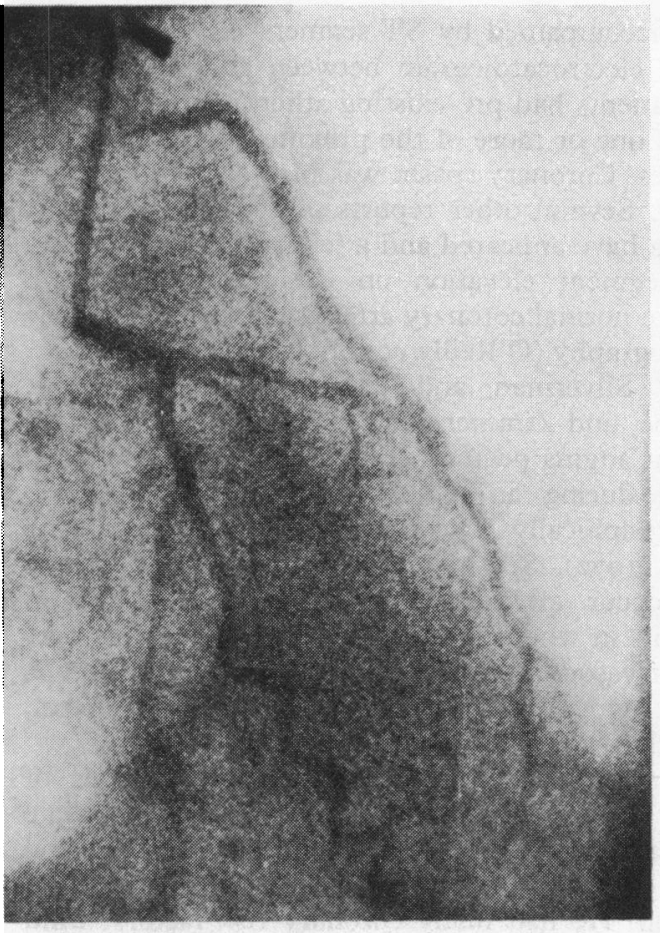

FIG. 2 Selective left coronary arteriogram after saphenous vein bypass grafting $\left(30^{\circ}\right.$ right anterior oblique position). The left main coronary artery is small and the venous bypass graft fills retrogradely. There are small areas of atheromatous narrowing of the left anterior descending artery, with an important stenosis in its proximal third. The vessels are tortuous.

The postoperative course was uneventful. The chest pain disappeared.

Four weeks later coronary arteriography was repeated. On this occasion $5 \mathrm{mg}$ sublingual isosorbide dinitrate was given before arteriography. Selective injections of Renografin were made into the venous graft, and into the right and left coronary arteries in several different projections: these showed a patent graft, a long and widely patent left main coronary artery, with atheroma in the left anterior descending artery (Fig. 2), and a normal right coronary artery. There was no change in blood pressure during injection into the venous graft or left coronary artery: during right coronary injection, a fall in blood pressure occurred and was accompanied by $T$ wave inversion.

\section{Discussion}

Prinzmetal et al. (1959) proposed spasm of a coronary artery as a cause for a characteristic anginal syndrome, associated with chest pain appearing at 
rest, accompanied by ST segment elevation, and a stable electrocardiogram between attacks. Most of the patients had pre-existing atheromatous narrowing of one or more of the proximal major coronary arteries. Coronary spasm was blamed as the trigger factor. Several other reports of Prinzmetal variant angina have appeared and a few patients had severe ST segment elevation on the electrocardiogram despite normal coronary arteries proven at coronary arteriography (O'Reilly et al., 1970; Whitting et al., 1970; Silverman and Flamm, 1971; Demany, Tambe, and Zimmerman, 1968). In a patient with variant angina pectoris spasm of the right coronary artery during an attack has been demonstrated angiographically (Oliva et al., 1973; Dhurandhar et al., 1972). Spasm of the coronary arteries may also occur after withdrawal of nitroglycerin in patients in whom chronic exposure has caused persistent vasodilatation (Lange et al., 1972). There is good evidence, therefore, that coronary spasm, though uncommon, does occur.

Our patient suffered from severe episodes of chest pain, thought to be caused by inadequate coronary blood flow, and was admitted to hospital twice for severe praecordial pain with $T$ wave inversion. He had many coronary risk factors: mild diabetes mellitus, type 4 hyperlipidaemia, and a history of heavy smoking. At coronary angiography he appeared to have severe stenosis of the left main coronary artery, developed cardiac standstill, lost consciousness, and required resuscitation: a diagnosis of left main coronary obstruction was made and further injections into the left coronary artery were not performed because of the possible risk to life. The severe $T$ wave changes which appeared during injection of contrast medium into the right coronary artery, which were accompanied by a transient fall in blood pressure, supported the suggestion of coronary artery obstruction. However, demonstration of a widely patent left main coronary artery a month after the operation, confirmed a preoperative suspicion that this was caused by spasm of the artery.

The cause of the coronary arterial spasm in this patient is uncertain: it may have been caused by mechanical irritation by the tip of the catheter, a result of injection of the contrast medium (Gensini et al., 1962; O'Reilly et al., 1970; Meaney and Buonocore, 1966; Wickbom and Bartley, 1957), or a consequence of an independent phenomenon responsible for the anginal syndrome. A mechanical factor or subintimal dissection cannot be excluded. The last two are unlikely since antecedent chest pain at home was accompanied by $T$ wave changes, and similar changes appeared during the right coronary angiogram. The postoperative improvement in the clinical syndrome is difficult to explain: it may be a placebo effect or a real improvement in left coronary blood flow during spasm. MacAlpin et al. (1973) and King et al. (1973) treated patients with variant angina pectoris by saphenous vein bypass grafts and had a high mortality and a low rate of improvement: they considered associated spasm of the vessel distal to the graft as the cause for lack of improvement.

The right coronary artery is more frequently involved in spasm (MacAlpin et al., 1973; Aisner, 1970; Kemp et al., 1973), and most reports on variant angina pectoris demonstrate ST elevation in the inferior leads (II, III, aVF), indicating involvement of the right coronary artery. Some believe this to be caused by a sphincter-like muscle at the orifice of the artery (Boucek, Takeshita, and Brady, 1965). Our patient is the first in whom left main coronary artery spasm has been reported. We remain uncertain whether spasm of the left main coronary artery has the same grave prognosis reputed to be associated with atheromatous narrowing of it. Severe spasm, however, may be a cause of angina pectoris (as in this patient), acute myocardial infarction, and even sudden death in the presence of normal coronary arteries (MacAlpin, 1973; Carmichael and Lieben, 1963).

\section{References}

Aisner, M. (1970). Angina pectoris 1968-1970 (Editorial). New England Fournal of Medicine, 282, 746.

Boucek, R. J., Takeshita, R., and Brady, A. H. (1965). Intimal hypertrophy in coronary arteries and considerations of the papillary muscle arteries (man). Anatomical Record, 153, 243.

Carmichael, P., and Lieben, J. (1963). Sudden death in explosives workers. Archives of Environmental Health, 7, 424.

Demany, M. A., Tambe, A., and Zimmerman, H. A. (1968). Coronary arterial spasm. Diseases of the Chest, 53, 714.

Dhurandhar, R. W., Watt, D. L., Silver, M. D., Trimble, A. S., and Adelman, A. G. (1972). Prinzmetal's variant form of angina with arteriographic evidence of coronary arterial spasm. American fournal of Cardiology, 30, 902.

Gensini, G. G., DiGiorgi, S., Murad-Netto, S., and Block, A. (1962). Arteriographic demonstration of coronary artery spasm and its release after the use of vasodilator in a case of angina pectoris and in the experimental animal. Angiology, 13, 550.

Gotsman, M. S., Bakst, A., Lewis, B. S., Mitha, A. S., and Reznik, M. L. (1973). Technical aspects of coronary angiography. South African Medical fournal, 47, 1037.

Judkins, M. P. (1967). Selective coronary arteriography. Radiology, 89, 815.

Kemp, H. G., Jr., Vokonas, P. S., Cohn, P. F., and Gorlin, R. (I973). The anginal syndrome associated with normal coronary arteriograms: report of a six year experience. American fournal of Medicine, 54, 735.

King, S. B., Mansour, K. A., Hatcher, C. R., Silverman, M. E., and Hart, N. C. (1973). Coronary artery spasm producing Prinzmetal's angina and myocardial infarction in the absence of coronary atherosclerosis: surgical treatment. Annals of Thoracic Surgery, 16, 337. 
Lange, R. L., Reid, M. S., Tresch, D. D., Keelan, M. H., Bernhard, V. M., and Coolidge, G. (1972). Nonatheromatous ischemic heart disease following withdrawal from chronic industrial nitroglycerin exposure. Circulation, 46, 666.

MacAlpin, R. (1973). Coronary spasm as a cause of angina (Editorial). New England fournal of Medicine, 288, 788.

MacAlpin, R. N., Kattus, A. A., and Alvaro, A. B. (1973). Angina pectoris at rest with preservation of exercise capacity: Prinzmetal's variant angina. Circulation, 47, 946.

Meaney, T. F., and Buonocore, E. (1966). Contractions of the renal arteries during arteriography. Radiology, 86, 4I.

Oliva, P. B., Potts, D. E., and Pluss, R. G. (1973). Coronary arterial spasm in Prinzmetal angina: documentation by coronary arteriography. New England fournal of Medicine, 288, 745 .

O'Reilly, R. J., Spellberg, R. D., and King, T. W. (1970). Recognition of proximal right coronary artery spasm during coronary arteriography. Radiology, 95, 305.
Prinzmetal, M., Kennamer, R., Merliss, R., Wada, T., and Bor, N. (1959). Angina pectoris I. A variant form of angina pectoris: preliminary report. American fournal of Medicine, 27, 375.

Silverman, M. E., and Flamm, M. D., Jr. (1971). Variant angina pectoris: anatomic findings and prognostic implications. Annals of Internal Medicine, 75, 339.

Whitting, R. B., Klein, M. D., Vander Veer, J., and Lown, B. (1970). Variant angina pectoris. New England fournal of Medicine, 282, 709.

Wickbom, I., and Bartley, O. (1957). Arterial 'spasm' in peripheral arteriography using the catheter method. Acta Radiologica, 47, 433 .

Requests for reprints to Professor Mervyn S. Gotsman, Mayer de Rothschild Hadassah University Hospital, Kiryat Hadassah, Jerusalem, Israel. 